\title{
SUSTENTAÇÃO ECONÔMICA DAS UNIVERSIDADES PÚBLICAS E GRATUIDADE
}

\author{
Sadi Dal Rosso*
}

AMARAL, Nelson Cardoso. Financiamento da educação superior: e Estado x mercado. São Paulo: Cortez; Piracicaba, SP: Editora UNIMEP, 2003. 214 p.

O ano de 2005 promete muito debate sobre a universidade pública brasileira, a considerar declarações recentes do Ministério da Educação e do Palácio do Planalto. Os atores interessados na questão da universidade pública vão muito além destes dois poderosos interlocutores. Os reitores e as autoridades universitárias querem ser ouvidos, e mais: querem poder interferir sobre o futuro do ensino superior público. Intelectuais e pesquisadores da área também elaboram críticas e, às vezes, apresentam propostas. A estrutura organizada dos docentes, dos servidores técnico-administrativos e dos estudantes, além de serem núcleos importantes de poder universitário, detêm contribuições acumuladas através do tempo em lutas e discussões. O movimento sindical não universitário, infelizmente, é um interlocutor menor na questão universitária, dado o distanciamento que a universidade mantém em relação aos trabalhadores e, consequientemente, a exigüidade de proposições a respeito do ensino superior público dentro do movimento dos trabalhadores. A sociedade em geral é a grande interessada na questão universitária uma vez que poderia beneficiar-se dela por meio do acesso ao ensino superior público, mas os canais pelos quais pode interferir sobre ela são diminutos, exceto por meio de movimentos organizados tais como o MST, o movimento negro, o movimento das

* Professor do Departamento de Sociologia da Universidade de Brasília. E-mail: sadi@unb.br 
mulheres e outros movimentos com bandeiras de ação definidas e com poder de intervenção.

Qual a grande questão que tomará o espaço dos debates universitários e a atenção destes atores sociais? Arriscaria afirmar que a sustentação econômica das universidades públicas é o nó górdio a ser desatado por qualquer agente que queira interferir nos destinos do ensino superior brasileiro. A sociedade está a exigir uma solução para tal questão. Ainda que a sustentação econômica refira-se apenas aos meios para a universidade pública exercer seu papel de produzir e transmitir conhecimentos novos, seu lugar na crise universitária é de tal magnitude que aparecerá como a questão mais importante e a principal a ser resolvida por uma reforma universitária.

Como é equacionada tal questão em outros contextos? Com algum grau de simplificação, podemos dividir as formas de sustentação econômica das universidades públicas em dois grandes modelos: o modelo das universidades públicas gratuitas, padrão cuja manifestação principal ocorre nos países europeus daí expandindo-se para países em desenvolvimento; e o modelo das universidades públicas pagas, que segue convencionalmente o padrão estadunidense de ensino superior público. Ambos os modelos foram responsáveis pelo significativo acesso da população daquelas nações ricas à formação universitária superior. Diferem entre si em muitos aspectos, mas o cerne da diferença está em um indicador: no modelo europeu, o financiamento integral do ensino superior público é estatal; no modelo estadunidense, o financiamento do ensino superior público somente em parte é estatal, sendo uma parte significativa da sustentação das universidades públicas coberta pelas anuidades pagas pelos estudantes. Ambos os modelos de sustentação econômica podem conviver com o ensino superior privado pago. Por exemplo, no caso do modelo europeu, sempre existiram as universidades confessionais, as universidades católicas, as universidades luteranas, etc., e, ultimamente, começam a aparecer as universidades-empresas. No modelo norte-americano, o ensino superior privado pago sempre foi uma constante.

No Brasil, a polêmica sobre a sustentação econômica do ensino superior público é histórica, tendo prevalecido, entre altos e baixos, a 
perspectiva do modelo europeu, a saber, o ensino superior público é gratuito. Nas décadas de 80 e 90 do século XX, no entanto, por força da redução do aporte estatal, as universidades públicas foram forçadas a produzir uma parte do seu sustento, mudança que não ocorreu sem implicações internas significativas na vida universitária, nem sem impactos na ordem jurídica. A constituição de setores de arrecadação de recursos dentro das universidades públicas alterou a estrutura de poder dentro das instituições - a mão que guarda a chave do cofre, também controla o poder. Dentro dessa política de arrecadação de recursos, as universidades públicas também passaram a vender cursos de toda a ordem - hoje a universidade pública está, em boa medida, privatizada por dentro - jogando na lata do lixo o princípio da gratuidade do ensino público em estabelecimentos oficiais, definido no artigo 206 da Constituição. Tais mudanças na cotidianidade das universidades públicas tomam lugar à revelia da definição política da sociedade a respeito dos rumos do financiamento das instituições públicas de ensino superior, como se fossem incursões em terra de ninguém, ao sabor da "capacidade empreendedora" dos dirigentes universitários.

A contribuição mais significativa dos últimos anos ao debate sobre a sustentação econômica das universidades públicas foi feito pelo valioso livro de Nelson Cardoso do Amaral, intitulado Financiamento da educação superior, estado x mercado. São 200 páginas de sólida argumentação, com respaldo em dados estatísticos que cobrem a década e meia entre os anos 1989 e 2002. As informações estatísticas são apresentadas de duas maneiras. Por um lado, tabelas e gráficos são utilizados como elementos demonstrativos na argumentação interna. Mas, o autor vai além e oferece uma segunda contribuição preciosa. O CD-ROM que acompanha o livro traz estatísticas e suas respectivas fontes, instituição por instituição, ano por ano, item por item, características que tornam o livro num reservatório inestimável e permanente de consulta.

Isto quanto a estatísticas. Teoricamente, o livro constrói sua base de sustentação no argumento de que as políticas liberais estão conduzindo as universidades públicas ao estado de crise de 
financiamento que conhecemos. "Elas foram forçadas, pela diminuição dos recursos próprios, a se dirigir ao mercado, à procura de fontes alternativas de recursos financeiros, por meio de prestação de serviços, oferecimento de cursos de especialização e extensão, consultorias, assessorias, cobrança de taxas, matrículas, serviços de laboratórios, etc." (p. 30). Tais mudanças fazem parte de uma privatização dissimulada e significam uma alteração muito profunda na ordem jurídica e social construída, ainda que não ativada, a partir de uma deliberação explícita do Congresso Nacional. "Está em curso uma verdadeira reforma universitária que utiliza o financiamento como um dos instrumentos essenciais para sua implantação, levando as IFES a se afastar de suas funções de elaboração de cultura, tornandose, cada vez mais, organizações utilitaristas, segundo as regras e a lógica do quase-mercado educacional" (p. 30). Os efeitos do liberalismo sobre as políticas de Estado são conhecidos, até certo ponto, nas singularidades dos campos de atuação, mas o emprego de meios de pressão econômica para produzir os efeitos de uma reforma universitária traz uma componente imprevista. Ou seja, na prática, está-se alterando profundamente a ordem jurídica da sociedade, sem que a instituição a quem compete a deliberação, a saber, o Congresso Nacional, seja chamado a se manifestar sobre qual a política que deva ser implementada. E se o Congresso Nacional não é ouvido, também o conjunto da sociedade fica impossibilitado de manifestarse através dos meios formais. Restam as formas de resistência como apresentadas pelos movimentos de estudantes, de servidores técnicoadministrativos e de docentes.

Nelson Cardoso Amaral vale-se do conceito de Fundo Público para analisar o financiamento do Estado para o ensino superior. $\mathrm{O}$ Fundo Público é constituído pelo pagamento, tanto por parte de capitalistas quanto por parte de trabalhadores, de impostos, contribuições e taxas, estabelecidos pelas leis do país. Com o Fundo Público, os governos mantêm as burocracias de Estado, fazem investimentos setoriais e, particularmente, pagam juros e encargos das dívidas acumuladas através dos anos. A questão que perpassa todo o livro é sobre os efeitos para as universidades públicas quando o Estado recua de seu compromisso de sustentá-las integralmente 
com recursos deste Fundo Público. Há pessoas, como é o caso de muitos reitores e dirigentes, que supõem estarmos passando por uma crise temporária, e, quando ultrapassada, serão retomados os padrões tradicionais de financiamento através do Fundo Público. Uma das grandes contribuições do livro consiste em levantar o debate sobre a política de sustentação das universidades públicas. Como devem ser elas sustentadas? Integralmente pelo Fundo Público? Devem os estudantes contribuir com a sustentação econômica das universidades públicas em que estudam? Quais os argumentos que sustentam as respectivas proposições?

Para analisar a sustentação econômica das universidades públicas, os argumentos são divididos em dois blocos: aqueles que são favoráveis à gratuidade das instituições estatais de ensino superior; e aqueles que defendem uma maior participação dos estudantes no custeio dos seus estudos universitários.

Dez argumentos são elencados a favor da gratuidade do ensino superior (p. 108), sobressaindo entre eles a importância da gratuidade para a difusão da cidadania e da democracia social em nossas sociedades. Este argumento tem contra si o fato de que as universidades públicas gratuitas abrigam uma significativa proporção de estudantes das classes mais bem aquinhoadas economicamente. Nos últimos anos, importantes reivindicações formuladas pelo movimento docente e de estudantes esbarraram contra o fato de que as universidades públicas com regime gratuito não respondem significativamente às demandas das camadas mais pobres da população. A universidade pública é uma instituição que envelheceu rapidamente, tornou-se conservadora. As demandas por mais verbas ou por mais contratações de professores não são acompanhadas de propostas de democratização do acesso ao ensino superior público para maiores contingentes de estudantes. O movimento docente, de servidores e de estudantes tende a trilhar o caminho do corporativismo à medida que não apresentar propostas concretas para o acesso de centenas de milhares de jovens ao ensino superior público. Relações alunos/professor que não ultrapassam os limites de 10 ou 15 estudantes para cada docente são intoleráveis em um país de miseráveis, iletrados 
e excluídos do acesso ao ensino superior gratuito, pelo simples fato de trabalhar para elites, quando a demanda é de milhões. Tanto no modelo da gratuidade do ensino superior público, cujo exemplo maior vem dos países europeus, quanto do modelo do ensino superior público pago, na forma existente nos Estados Unidos da América do Norte, as universidades de massa são uma realidade, que não afeta a qualidade da formação. No Brasil, a rejeição sistemática de ampliar a relação estudante/professor sob o argumento da defesa da qualidade não passa de uma vil defesa de um corporativismo cego e de uma negação disfarçada do acesso ao ensino superior público e gratuito a centenas de milhares de jovens estudantes brasileiros, portanto uma ação contra a democracia de acesso ao ensino universitário público, bem como contra a expansão da cidadania. A subutilização das estruturas universitárias nos períodos vespertino e noturno são outro indicador gritante de como a universidade tornou-se conservadora e não se abriu para as necessidades da sociedade.

Este fechamento da universidade pública e gratuita sobre si mesma aparece em outros indicadores, como a ridícula participação de afro-descendentes, de descendentes de índios e de outras minorias excluídas ao ensino universitário. À medida que as universidades fecham-se para estes grupos, perdem as vantagens que adviriam da diversidade da composição do corpo estudantil e de professores e a introdução de outras preocupações culturais e intelectuais.

Nada justifica a redução dos investimentos do Estado no ensino superior público e gratuito entre 1991 e 2002, como demonstrado pelos dados apresentados por Nelson Cardoso do Amaral (p. 144145). A estrutura de ensino público gratuito, a despeito de formidável, é insuficiente para atender às necessidades de um país como o Brasil. Por isso, o governo precisa investir mais em educação para que o Brasil possa deixar a posição de país com um dos menores índices de população jovem estudando em instituições de ensino superior na América Latina, apenas na América Latina. Esperar que o ensino privado venha a resolver este problema parece ser uma proposta sem saída, uma vez que a maioria daqueles que estão fora do circuito do ensino superior, estão em tal posição simplesmente por não terem 
meios de pagar mensalidades em universidades do sistema privado, já que o acesso ao ensino superior gratuito é mais difícil. Talvez uma consistente política de ensino superior público e gratuito à distância possa abrir caminho para se encontrar uma alternativa de solução a este problema.

A definição do ensino gratuito em estabelecimentos oficiais princípio constitucional que é sistematicamente solapado pelas medidas de captação de recursos aplicadas pelas administrações gerenciais que presidem nossas universidades, faculdades, institutos e centros, na difusão de cursos pagos através das Escolas de Línguas, das Escolas de Extensão, dos Mestrados Profissionalizantes, dos cursos de Aperfeiçoamento e de Especialização, todo um monumental sistema que está sendo montado para solapar o princípio constitucional da gratuidade diante do aguilhão da falta de repasse de recursos do Fundo Público - é uma conquista recente, apenas da Constituição de 1988. A manutenção de universidades públicas e gratuitas na maioria dos Estados brasileiros respondeu a um entendimento de um Estado desenvolvimentista e à luta de estudantes especialmente. Em um país em que o ensino superior foi sempre um produto para a elite econômica e política, ainda que modernizante, como foi o caso da Universidade de São Paulo e das Universidades Federais nas capitais dos Estados, não causaria espanto que o ensino superior fosse pago, pois as elites sempre detiveram meios para pagá-lo. A expansão do ensino superior gratuito responde a uma combinação muito particular de ação de grupos de intelectuais, junto com estudantes, num contexto de uma política desenvolvimentista com forte intervenção do Estado.

Se a noção de desenvolvimentismo capitalista hoje está bastante abalada, isto implica que precisamos re-elaborar conceitualmente a noção de desenvolvimento, a qual, em relação ao ensino superior, não poderá deixar de incluir a abertura do acesso para centenas de milhares de jovens que concluíram o segundo grau e não conseguem, por falta de recursos, adentrar quaisquer estabelecimentos de ensino superior, bem como a democratização para grupos diferenciados que sempre estiveram sistematicamente alijados do ensino superior. Este é o conceito de desenvolvimento que se espera de um país que tantas mazelas ostenta em sua história. 
Na história da educação superior brasileira, a preservação do princípio da gratuidade é um tema pouco conhecido. Mesmo quando constituídas as primeiras universidades públicas pelo Estado, grupos defendiam o pagamento das matrículas e taxas escolares por parte dos estudantes, provenientes em grande medida dos estratos superiores da sociedade. Podemos dizer que foi uma longa ação política dos movimentos sociais que conseguiu gravar na Constituição de 1988 o princípio da gratuidade em estabelecimentos oficiais, sendo, portanto uma conquista da modernidade, dos movimentos progressistas na sociedade brasileira.

Na era liberal, a gratuidade é atacada por grupos internos e externos. Talvez a maior pressão provenha dos grupos externos, ligados aos grandes bancos e às grandes organizações internacionais que conseguem exercer influência sobre o campo educacional. Há um bloco de forças que vincula segmentos sociais nacionais - entre os quais se incluem alguns segmentos ditos progressistas que se incrustam nas universidades, vendendo cursos de aperfeiçoamento, de especialização e participando da farra que é privatização disfarçada da universidade pública - e internacionais, que se batem a favor do pagamento de matrículas pelos estudantes universitários do setor público. Armam-se de poderosos argumentos, sintetizados por Nelson Cardoso do Amaral às páginas 109 e 110 de seu interessante livro. Dentre todos, destaca-se o argumento da desigualdade. As universidades públicas gratuitas receberiam maior contingente de estudantes dos estratos mais bem situados da sociedade, conseqüentemente, a gratuidade conduz à manutenção da desigualdade social. Em decorrência, o pagamento das universidades seria uma medida que ampliaria a igualdade social. Este argumento contém partes de verdade. Nas universidades públicas, que até o momento são as melhores qualitativamente, ingressam importantes segmentos de estudantes das camadas sociais mais ricas. Tal fato também não invalida a verdade de que freqüentam os bancos universitários muitos estudantes pobres ou provenientes de camadas sociais remediadas. Se introduzido o pagamento das universidades públicas pelos estudantes, fechar-se-ia este instrumento de ascensão social para as camadas pobres e remediadas. Retrucam os privatistas: 
dêem-se bolsas aos estudantes pobres! Quer-se, então, que os pobres dependam de políticas compensatórias e, pior ainda, de políticas temporárias e provisórias. A tais políticas de favores, é preferível a noção geral de que o Estado deva manter o ensino superior público gratuito, o qual fortalece a cidadania e a democracia indistintamente, e reformar o acesso à universidade gratuita de maneira que os pobres e os excluídos obtenham acesso a ela. Então, o acesso ao ensino superior gratuito transforma-se em questão crucial para o sistema da gratuidade. Neste sentido, as universidades não vêm respondendo bem. Medidas como os sistemas de avaliação mediante o exame dos estudantes durante os três anos do segundo grau até agora não deram quaisquer indicações de terem avançado neste aspecto de ampliar o acesso da universidade gratuita aos setores excluídos. Ao contrário, existem fundadas dúvidas que a imposição de exames seqüenciais conduz a uma seleção econômica ainda maior da universidade pública, além de antecipar o estresse sobre a cabeça dos adolescentes.

Se a questão do acesso é uma questão crucial para, de fato, valer o entendimento de que o ensino superior público promove a cidadania dos cidadãos e o desenvolvimento social, nossas universidades precisam reformar-se ou serem reformadas com estes objetivos. Mantidas as estruturas obsoletas e arcaicas atualmente existentes, bem como as políticas de acesso que inviabilizam a entrada de jovens provenientes de segmentos mais pobres ou portadores de marcas históricas de exclusão nas universidades gratuitas, os grupos sociais que defendem o ensino superior gratuito terão contra si sérias provas contrafactuais para sustentar o princípio constitucional da gratuidade. 
